Article

\title{
A New Player for Tackling Inequalities? Framing the Social Value and Impact of the Maker Movement
}

\author{
Elisabeth Unterfrauner ${ }^{1}$, Margit Hofer ${ }^{1}$, Bastian Pelka ${ }^{2, *}$ and Marthe Zirngiebl ${ }^{2}$ \\ ${ }^{1}$ Centre for Social Innovation, 1150 Vienna, Austria; E-Mails: unterfrauner@zsi.at (E.U.), hofer@zsi.at (M.H.) \\ 2 Social Research Centre, TU Dortmund, 44339 Dortmund, Germany; E-Mails: bastian.pelka@tu-dortmund.de (B.P.), \\ marthe.zirngiebl@tu-dortmund.de (M.Z.)
}

* Corresponding author

Submitted: 30 October 2019 | Accepted: 19 December 2019 | Published: 14 May 2020

\begin{abstract}
The Maker Movement has raised great expectations towards its potential for tackling social inequalities by mediating technology-related skills to everybody. Are maker spaces new players for social inclusion in digital societies? How can this potential impact be framed? While scientific discourse has so far identified broad value and impact dimensions of the Maker Movement, this article adds empirical insight into the potential for tackling social inequalities. The study is based on 39 interviews with makers and managers of maker initiatives and ten self-reporting surveys filled in by maker initiative managers throughout Europe, which have been analyzed qualitatively. We found four main domains in which makers address social inclusion: First, by mediating skills and competences not only in the field of digital technologies but in the broader sense of empowering people to "make" solutions for encountered problems. Second, we found that makers actively strive to provide democratized access to digital fabrication and the knowledge on how to use them. Third and fourth, we found different ambitions articulated by makers to change society and social practices towards a society providing better opportunities for individuals. As an entry point for further research and actions, we derived a maker typology that reflects the diverse and various types of relationships to be found in the maker community. This typology could be used for exploring further collaborations between social actors and the Maker Movement. We conclude with an outlook on potential trajectories of the Maker Movement and specify which could influence the inclusion of marginalized persons.
\end{abstract}

\section{Keywords}

Maker Movement; maker space; social impact; social inclusion; social inequalities

\section{Issue}

This article is part of the issue "Digital Inclusion Across the Globe: What Is Being Done to Tackle Digital Inequities?" edited by Bianca C. Reisdorf (University of North Carolina at Charlotte, USA) and Colin Rhinesmith (Simmons University, USA).

(C) 2020 by the authors; licensee Cogitatio (Lisbon, Portugal). This article is licensed under a Creative Commons Attribution 4.0 International License (CC BY).

\section{Introduction}

Marginalization that might ultimately lead to exclusion from society has been described as a multidimensional process of "progressive social rupture, detaching groups and individuals from social relations and institutions and preventing them from a full participation in the...normatively prescribed activities by the society in which they live" (Silver, 2007, p. 15). Marginalization takes place in different dimensions such as the educational di- mension, the labor dimension, or the social dimension, to name but a few. Processes of exclusion and marginalization are not limited to the aforementioned dimensions but concern the digital life as well. The digital divide indicates a gap between those who have access to the Internet and information and communication technologies and those who do not, resulting ultimately in a "second digital divide" where the latter lag behind in their skills development. Those most affected are already marginalized people who usually lack access to many dif- 
ferent kinds of resources (Yu, 2006). Social inclusion aims to overcome marginalization and exclusion by initiating a "process of improving the terms for individuals and groups to take part in society, and...[a] process of improving the ability, opportunity, and dignity of those disadvantaged on the basis of their identity to take part in society" (World Bank, n.d.). Hence, social inclusion acknowledges the underlying structural circumstances which exclude people at risk and postulates that these have to be tackled instead of solely looking at the role of excluded individuals and their active attempt to participate in social life. Thereby, just as marginalization takes place in different social dimensions, inclusion refers to the economic, social, political, and cultural sphere which might be regarded as separate but are highly intertwined (Kronauer, 1996).

The Maker Movement, with its claim of being open and providing democratized access to modern fabrication technologies and to equip citizens with crucial 21st century digital skills, might counteract the processes of exclusion for people at risk and contribute to closing the digital divide. Makers are driven by doing something with their own hands, combining traditional crafting skills and tools with digital fabrication know-how such as 3D printers, laser cutters, etc. and engage in a physical community, in a maker space or so-called FabLab, and further virtual communities where knowledge and experiences are shared. Makers strive to create individualized solutions for issues and problems that they encounter in their day-to-day lives (e.g., Awori \& Lee, 2017; Buehler, Hurst, \& Hofmann, 2014; Korhonen, Parkka, \& van Gils, 2003) such as disability, special needs (Bosse, Krüger, Linke, \& Pelka, 2019), and environmental issues (e.g., Kohtala, 2015; Kohtala \& Hyysalo, 2015). Thus, maker communities create and capture social value and strive to support inclusion. They build "new forms of local, bottomup business, social and sustainable models, traversing between non-monetized and monetized accounting frameworks" (Millard et al., 2016, p. 54).

Maker spaces that commit to public opening hours are interesting spaces for empowerment and learningespecially for competences linked to the world of technology. While local spaces clearly address their local target groups' needs, the Maker Movement at large also aims at challenging societal issues. Thus, the aim of this article is to understand the impact of the Maker Movement on inclusion and empowerment and to identify opportunities for people at risk of exclusion.

The research question of this article is: Are there any indications that makers can be interesting players for social inclusion issues?

This article will investigate the social value and potential impact of the Maker Movement from the perspective of makers and managers of maker spaces. To answer the research question, we analyzed 39 interviews with makers (29 maker interviews) and managers of maker initiatives (10 manager interviews) and ten self-reporting surveys filled in by maker initiative managers throughout Europe.

\section{Background: Social Impact Potential of Making}

Since the impact on the macro level accrues to the wider community, i.e., groups or "society" to which the initiative contributes alongside other initiatives or policies, it can hardly be traced back to single activities (Millard et al., 2016). Instead, we focus on the purpose of the activities pursued in the maker initiatives as well as the outcomes on the micro-level. Outcomes as well as impacts are neither purely beneficial nor harmful and can be perceived differently by different actors in society. Thus, we pay special attention to the individual maker's impact intentions and potential conflicts and use this perspective as a methodological background for our research.

Looking at key publications such as Make magazine might convey the impression of one united movement coming together on the promise of a better world brought about by the emergence of new digital fabrication technology (Nascimento \& Pólvora, 2018). Yet, as Nascimento and Pólvora (2018) show, the Maker Movement is actually made up of different initiatives with a diverse set of activities and goals instead of being a homogenous global movement. Taking this as a background, our research is directed at understanding the potential of different makers, or groups or types of makers, for tackling inequalities. Building upon the assumption of a heterogeneous movement allows for looking at nuances in impact aspirations and possible conflicts, rather than searching for signs of what has been promised by early pioneers of the movement. To guide our data collection, we collected potential impact areas of the maker community in the field of social inclusion on the base of a literature review.

From early on, STEAM subjects (Science, Technology, Engineering, Arts, Mathematics) or STEM education has recognized the value of maker education for these subjects by offering hands-on learning activities (Dougherty, 2016; Hwang, 2017; Papavlasopoulou, Giannakos, \& Jaccheri, 2016). STE(A)M education is seen as a way to bring children from less privileged backgrounds, as well as women, into more technical occupations. To do so, educators increasingly make use of the pedagogy of making (c.f. Papavlasopoulou et al., 2016; Voigt, Unterfrauner, Aslan, \& Hofer, 2019), which focuses on hands-on learning, opening black boxes, developing and realizing one's own ideas, and also the development of entrepreneurial skills. In short: Making is founded on "learning by doing" principles (Papert, 1994).

Thereby, empowerment is addressed in multiple ways, such as: (1) empowerment by the act of creating some tangible objects autonomously; and (2) empowerment through hands-on experience supporting knowledge of technology (Nascimento, 2014). The ultimate outcome of education enabling empowerment is that of inclusion and marginalized people empowered by maker communities. Firstly, they might become part of a maker community and secondly, via the new skills acquired, be included in the digital society, often especially linked to 
labor market inclusion. Besides fostering inclusiveness by empowering marginalized groups via targeted workshops and programs, maker spaces can be designed in such a way that allows for the participation of diverse groups (Nascimento, 2014). Finally, the products and services developed in maker communities can address societal challenges directly (Unterfrauner \& Voigt, 2017). Of special interest in this regard is the notion of shared value creation (Porter \& Kramer, 2011). Hybrid forms of value creation, combining economic and social value, are coined "shared value creation" (Porter \& Kramer, 2011). This implies making good products for customers as well as society at large by focusing more on the fulfillment of social needs or addressing societal challenges rather than pure profit maximization.

\section{Methodology: Expert Interviews with Makers and Maker Managers and Self-Reporting Survey}

Using this background for a methodological design, we decided to draw data directly from makers and maker space managers, building on a critical literature review that was used to pre-define three research pillars: (1) organization and governance; (2) peer and collaborative behaviors; and ( 3 ) impact and value creation. In order to have a sample that would allow building a typology that would encompass different strands of the maker culture, we applied a purposeful sampling strategy with pre-defined relevant and differentiating characteristics (Creswell, 2007; Merriam, 2009; Miles \& Huberman, 1994). We chose ten maker initiatives in eight European countries. These maker initiatives were selected after a mapping exercise based on the two dimensions, with as diverse a distribution as possible (see Figure 1). The two dimensions were chosen as best representing the diversity of social collective movements, by differentiating between different types and configurations of maker activities, namely (1) the scale and interaction dimension as an indicator for the connectedness between makers and (2) the social innovation dimension (Sestini, 2012). The scale and interaction dimensions range from single to network, i.e., from makers who work on their own to a network of strongly connected maker initiatives with distributed awareness, where glocal solutions are found and shared. On the vertical axis, at one end of the spectrum, single actors operate on a situational awareness level as they tend to be relatively isolated, unconnected, and focused more on a specific or local level and aim to find solutions that they personally and situationally encounter. At the other end of the axis, distributed awareness is created through strongly connected makers who collaboratively work on typically large and extensive areas. These distribute, adapt, and apply solutions that are shared in the maker community on a major scale (Salmon, Stanton, \& Jenkins, 2017).

The second dimension, on the horizontal axis, is the social innovation dimension that spans from social demand (tackling single social problems individually) to systemic change (broader societal change; Franz, Hochgerner, \& Howaldt, 2012; Grimm, Fox, Baines, \& Albertson, 2013). Social innovation is defined as an intentional and successful attempt to modify existing social practices or to enable new ones, which create change on a more or less systemic level (Hochgerner, 2013).

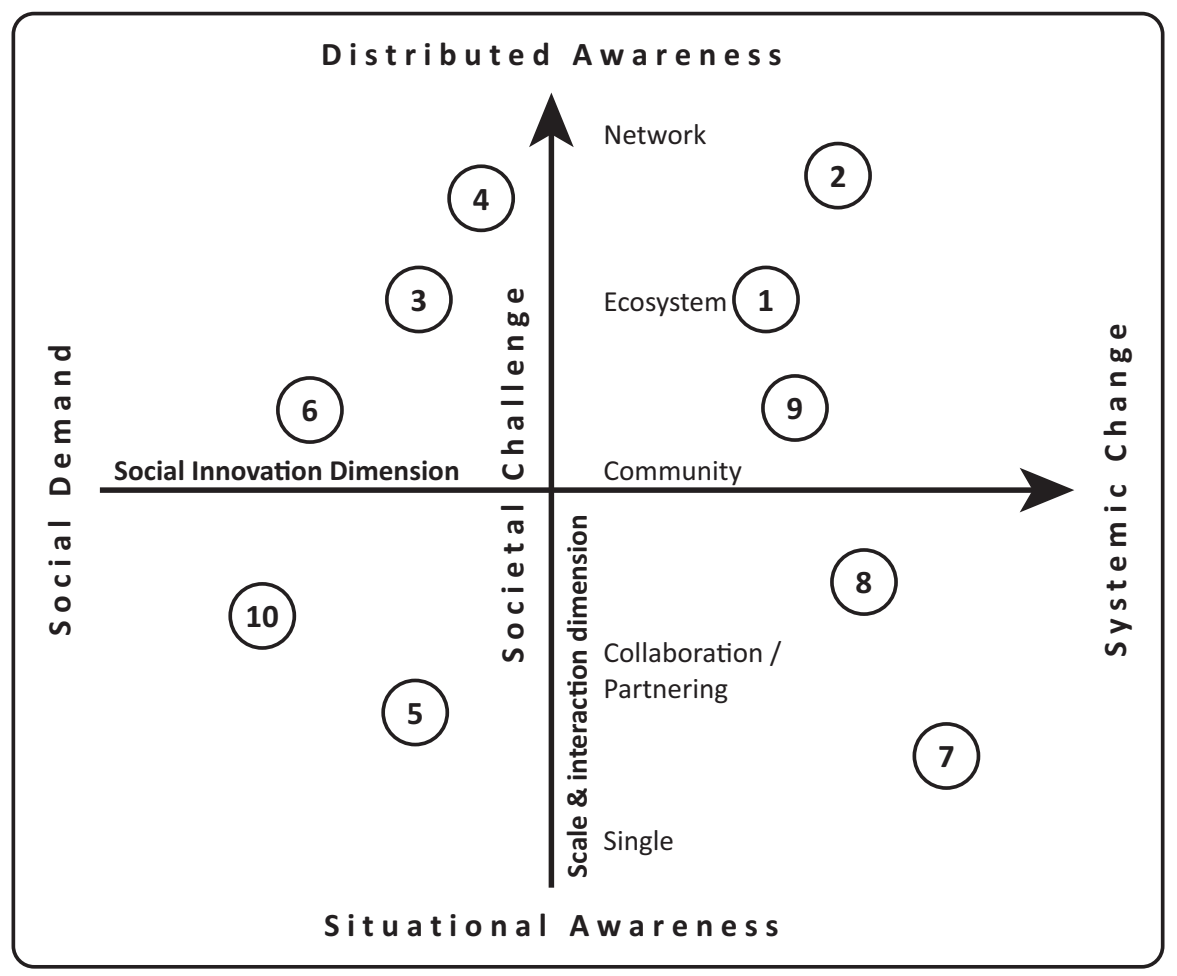

Figure 1. Scale and social innovation dimension (adapted from Millard et al., 2016, p. 63). 
Drawing on Murray, Caulier-Grice, and Mulgan (2010) and Bria et al. (2015), it can be described as a continuum of social change outcomes and impacts. At the one end, social innovations respond to social demand on a micro level, i.e., societal and technological innovations are developed that respond to social demands of individuals, sectors, or localities. On the other end, social innovations operate on a macro-level, enabling systemic change, i.e., societal and technological innovations are developed that affect the underlying structures, relationships and powers of society.

The initiatives were information-rich cases that differed in terms of organization and (social) innovation dimension-from a Mini Maker Faire to FabLabs and maker spaces., i.e., DTI lab (DTI, 1), Denmark; FabLab Barcelona (IAAC, 2), Spain; Arduino (3), Italy; Regional Metalworking Network (RMN, 4), the Netherlands; Mini Maker Faire Tartu (AHHAA, 5), Estonia; Happylab Vienna (HLW, 6), Austria; Dezentrale (7), Germany; HRW Lab (HRW, 8), Germany, Create It Real (CIR, 9), Denmark; and FabLab Zagreb (FLZ, 10), Croatia.

We chose explorative expert interviews as a qualitative method of choice (Bogner, Littig, \& Menz, 2009) and developed semi-structured interview guidelines (Drever, 2003) for makers and maker initiative managers to be used in a flexible manner while still preserving coverage of similar topics across multiple interviews. In expert interviews, interviewees are considered experts in a specific field; in our case, they were experts on a particular maker initiative as they were managing the initiative or makers in the community of that initiative. The gathered data represents their views and perspectives.

The interview guideline for makers consisted of 19 questions based on the pre-defined three potential impact pillars: eight dealt with making (personal trajectory, kind of activities, development of skills, etc.), four with the maker space they were visiting (kind of engagement activities, etc.) and the remaining six addressed value creation and impact, which is the focus of this article (cf. complete guideline in the supplementary material). The interview guideline for maker initiative managers was structured in a similar way but included questions regarding the organization and peer and collaborative behaviors (cf. complete guideline in the supplementary material). Additionally, the maker initiative managers completed a self-reporting survey consisting of 11 openended questions. The transcripts of the interviews, as well as the surveys, were analyzed qualitatively (Mayring, 2010) following a hybrid process of deductive (derived from the research questions) and inductive coding approaches (evolved from the interview data allowing for the unexpected; Flick, 2014). The purposes for also using an inductive approach are for once, supporting to condense raw textual data and to establish clear links between the evaluation or research objectives and the summary findings derived from the raw data. Further, it allows establishing a framework of the underlying structure of experiences or processes that are evident in the raw data (Thomas, 2006). Thus, it enriches the identification of additional themes allowing a direct emergence from the data using an inductive coding process.

This coding process involved the recognition of an important issue and encoding it prior to a process of interpretation (Boyatzis, 1998). Within the process, only codes that would capture a qualitative richness were included and respective themes developed consequently.

\section{Findings and Outcomes}

The analysis shows that the maker manager and maker perspective complemented each other very well. While managers tended to focus on a strategic level, e.g., shared their mission and vision for the maker initiative and which (social) scope the initiative should address, makers brought in their individual maker experience and shared their personal trajectory and examples of dealing with socially relevant questions in the maker community. Thus, the answers did not contradict each other but rather brought in different layers of observations and thoughts.

In total, 77 codings for social impact of the maker community (the third research pillar-impact and value creation) evolved in the hybrid coding process (inductive and deductive) referring to the four codes: education, inclusion, products addressing societal challenges, and from consuming to creating. An additional cluster of codes referring to clashes in the Maker Movement evolved as transversal topics in the inductive coding process.

\subsection{Education}

Education through making was mentioned in the interviews as one of the most important values and impacts. All maker initiatives in our sample were engaged in ongoing collaborations with educational institutions, from kindergartens up to university level. Two of the cases, FLZ and IAAC, were part of the architecture faculty and therefore had many student members. They either offered workshops at their premises or organized events at schools or even lent machines to trained teachers. Typically, the workshops were held under the umbrella of STEAM or STEM education. Maker initiatives provide room for the education of kids and young adults who are usually remote from education and therefore empower them as our interviewees claimed. Furthermore, Maker initiatives have the potential to break barriers and give access to people from different social backgrounds:

Part of the task which we set ourselves is, of course, to try to break barriers, especially for pupils who would never get the idea to study because they grow up in a social environment where they have no contact at all to universities...social origin determines the educational career a lot here [Germany]. And one of our tasks, which we set out to do, is to provide a bit of 
support there....When I say we were successful here, even though we have no proper measuring tool for it. (Manager, HRW)

The educational ambitions of interviewed makers included educating children, changing the relationship between consumers and producers, and ultimately supporting a mentality shift with respect to consumerism. Maker education has societal relevance as some interviewees said, as it prepares children for the future, not only in terms of 21st-century skills but also in terms of active engagement and critical reflection. Several makers underlined the importance of maker education for society: "I am often asked why I approach schools. It is not for money but because I think it adds value to society in the future." (Manager, FLZ) Additionally, the manager at DTI underlined the educational impact of maker initiatives and its importance for society:

It is all about providing people with knowledge and tools that make them become more valuable, whatever they do. It is giving them knowledge, practical tools, and approaches that sort of strengthen their capabilities. So education is really important...educating and training people to have a more open collaborative sort of customer-oriented and failure-oriented mindset is very key to us. (Manager, DTI)

According to the interviewees, maker pedagogy would add value to more traditional pedagogical approaches as it offers different learning experiences, but the interviewees reported no evidence of uptake of maker activities in formal education. Further research should investigate this from the viewpoint of formal education institutions, as our research is limited to the perspective of makers.

\subsection{Inclusion}

All analyzed cases showed a high commitment to the value of openness in the sense that their facilities including machines and knowledge were open to everybody. The maker spaces were accessible for the public, at least at certain hours. Openness is further ensured by signing the FabLab charter for those initiatives that want to be recognized as such. Democratized access to digital fabrication and the knowledge on how to use it would further close digital divides locally around the maker initiative, as the interviewees anticipated. We also found a high interest of many makers towards inclusion and the ambition to make their maker spaces usable to marginalized persons, especially people with disabilities. However, the analysis shows that equal participation of diverse groups is hardly the reality in most cases. Instead, male makers between the ages of 25 and 35 years with a higher educational background and very often with a technological affinity are the most prominent users of maker spaces. One reason could be found in the fact that makers have no experience in working with marginalized persons. Maker initiatives described a different level of awareness regarding inclusion. Noticeably, some tried to engage disadvantaged groups very actively, e.g., by installing a senior design lab, which was meant to attract retired people, with the aim to build on their more traditional crafts skills and combine it with digital fabrication skills. Other examples were mobile pop-up maker spaces that could be brought to disadvantaged neighborhoods. Mobile stations were also brought to refugee camps in yet another initiative not only to empower people but also to develop tools for immediate necessities. Maker initiatives also had an empowering function for unemployed people. The interpretation of the data suggests that the design of the maker space, as well as the educational offers and the facilitators in the maker space, have an impact on the participation of diverse groups. For instance, in maker spaces with female facilitators, the participation of female members was higher.

\subsection{Products Addressing Societal Challenges}

Many makers showed social ambitions in their doing and developed products addressing specific societal challenges. These resulted either from the engagement of individuals or from organized events such as makerthons in maker spaces. Makerthons, in reference to Hackathons, are events where makers come together with the aim to find solutions for (social) problems. In one maker space, for instance, a makerthon was used to develop a "growing" wheelchair, which could be used from childhood to adulthood by only substituting a few parts and thus making the wheelchair far more economical than conventional ones that have to be replaced completely.

Also, a variety of assistive technologies have been developed in the analyzed cases: a golf tee for persons with a wheelchair, a customized spoon, or a grid to put on the tablet PC that makes it easier to navigate for a person with physical impairments of the hand. Prostheses were also developed:

I printed two prosthetic covers for a leg and it was a joint operation with me printing and another designing it....The social thing about it was that it was ninety times cheaper than what he would have gotten...[compared to the] traditional way and...to be able to help someone, and still make some money....So I think this is important that you can add more value to whatever you do. (Maker, FLZ)

Maker spaces were used by parents, who sought technical solutions for their children with special needs, and "they can do this by networking with other parents and supporting each other, for example, creating special joysticks that can interact with computers and videogames" (Maker, Arduino).

Other ideas addressed the sustainable production and consumption of food, e.g., vertical gardening projects or hydroponic installations to grow plants with- 
out soil in private households. These ideas often dealt with local solutions addressing local problems leading to "new localism" but some might also be taken up globally (glocal solutions).

\subsection{From Consuming to Creating}

One of the key ways for organizations to create shared value opportunities is by re-conceiving products and markets (Porter \& Kramer, 2011). It implies improving products (again) for customers and society at large by stressing more on the fulfillment of basic societal needs.

The Maker Movement and individual maker initiatives enable such a re-conceptualization of products and markets. They transform pure consumers towards a combination of creators and consumers. By creating their own products, makers personalize and adapt things according to their needs while abandoning unnecessary waste and inventory keeping.

Concluding this chapter, overall with respect to the social value and impact dimension, $\operatorname{STE}(A) M$ education, maker pedagogy and inclusion were mentioned by the interviewees. Furthermore, in terms of inclusion, it shows a clash between the idea of inclusive maker spaces, which grant access for anybody, and the actual membership data, showing little evidence of members from marginalized groups. On the other hand, we found inspiring initiatives targeted at specific disadvantaged groups.

\subsection{The Maker Movement, Seen from a "Clashes" Perspective}

Our data reveal conflicts within the Maker Movement on the one side, but also between makers and other actors who are active in the thematic fields addressed by makers - such as education, innovation, inclusion or employment. In the following, we will use these "clashes" as a background for analyzing the potential impact of the Maker Movement for counteracting the processes of ex- clusion for people at risk and closing the digital divide. In that regard, two clashes that deserve special attention are presented.

While many makers follow "an anti-consumerist attitude" (Devendorf \& Rosner, 2015; Unterfrauner, Voigt, Schrammel, \& Menichinelli, 2017), we also see makers who align their activities with economic innovation, entrepreneurship, employment, career development, or the production of marketable products or pilots. Our data shed light on contradictory developments, such as maker spaces that run for profit and actively support patent applications and those that urge their users to share all the ideas developed in their spaces with all members. The results of this clash are unclear, but looking at the inclusion of people at risk, paying for a membership and making in a competitive, entrepreneurial environment might foster exclusion instead. Our data also reveal clashes between the Maker Movement and long "existing" institutions, such as schools, enterprises, universities, or civil society actors. Makers report that the culture prevailing in public spaces does not "fit" to that of the Maker Movement manifested in examples such as opening hours, regulations for data processing, or food and drink consumption, the accessibility for "unknown" people or procurement procedures. The multitude of collaborations with different forms of "existing" spaces-like schools, museums or libraries-indicates that the Maker Movement is in a process of liaising with other actors and that the impact potential highly relies on their attitude towards social inclusion.

Figure 2 shows the most salient positive and negative aspects in relation to the social value and impact dimension of the Maker Movement.

\section{Synthesis: The "Clashes" Perspective Leading to a "Typology of Makers"}

The described clashes with their different attitudes to "openness," "market," or "making" (in the following re-

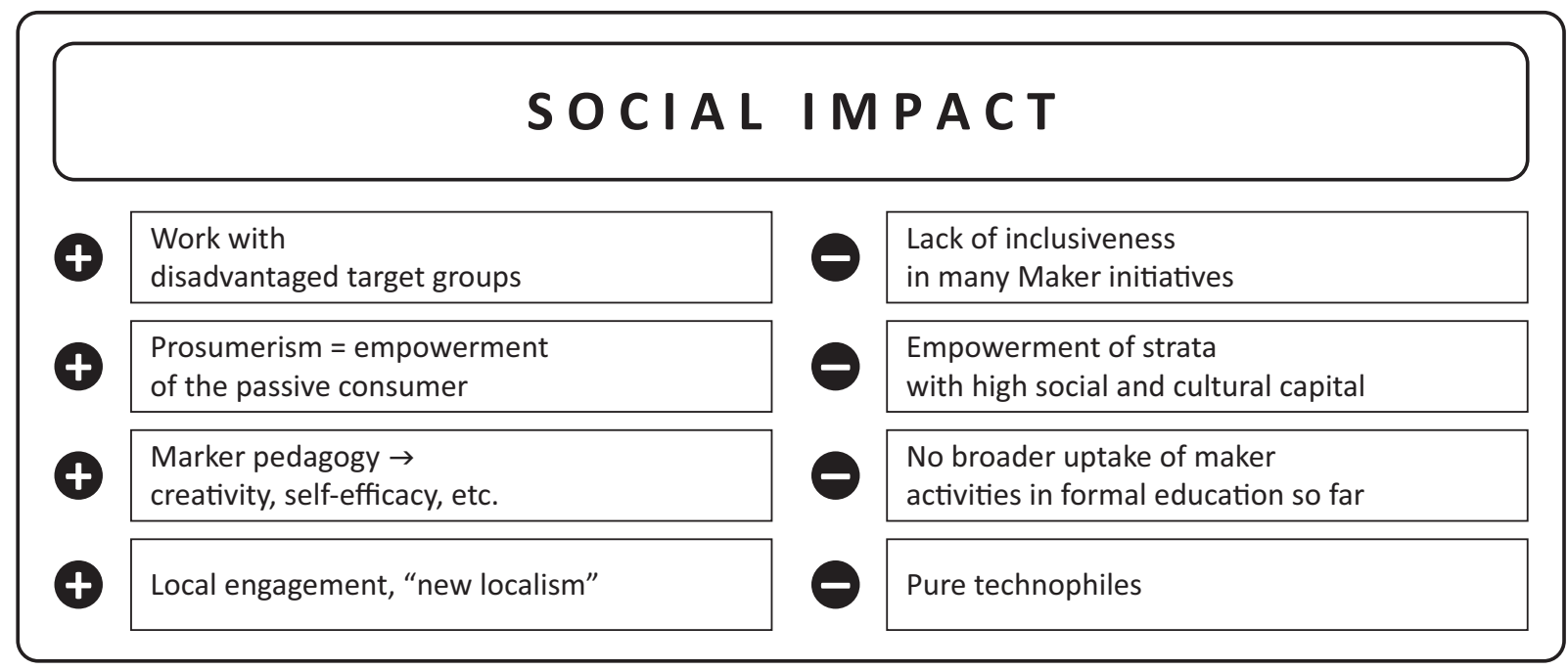

Figure 2. Differentiated perspective on the social impact of the Maker Movement. 
ferred to as three "cultural fields") in specific groups of makers could lead to a differentiation of "types" of makers with differentiated sets of attitudes, behaviors, and aims. We suggest an intra-differentiation of the Maker Movement that allows tracing impact in social spheres and therefore contributes to answering our research question. This intra-differentiation follows the three cultural fields, but differentiates depending on the way that a type of maker subscribes to them.

As a first cultural field, the openness of ideas is one of the central pillars of the Maker Movement. This is exemplified by many makers relying on the importance of sharing their work and using the work of others as well as by the broad variety and impact of sharing platforms heavily used by makers. However, makers who try to achieve economic revenues with their activities contest openness. We state that some makers value openness very high but found that makers aiming at financial exploitation of their making seem to value openness less. A second cultural field assembles around attitudes towards marketability of making-examples identified in the case are linked to job creation, career-building, or inventing marketable products or patents. Aside from openness and economic aims, we found a third cultural field: makers who make for the sake of making. We found evidence of makers who pursue different and changing goals of their making and reveal a high fascination with the process of making itself. Makers valuing the attribute "making" as high often also value "openness" as high.

Taking these three cultural fields, which comprise attitudes, activities, and behaviors as a field of differentiation, our cases suggest further differentiating five types of makers at the intersections of these fields (see also Figure 3 ). We deduced these five types by analyzing the makers' attitudes and assigning them to the cultural fields through a coding process:
1. The first type, "utopian makers," perceives maker values as incompatible with market values or disassociates from market values. Makers of this type value openness very highly and show a fascination for technology and the process of "making";

2. The second type, "pragmatic makers," analyses this ambiguity and recognizes the opportunity to go beyond the traditional dichotomy between openness and market;

3. The third type, "social makers," characterizes makers for whom openness is a key to reduce entry barriers to the market. Many makers of this type identify themselves as part of a community rather than individual makers. Makers of this type often pursue less technical aims and link their activities to education, inclusion, or environmental protection;

4. The fourth type, "making to market makers," gathers cases where proprietary ways are favored to commercialize maker products. Attending maker spaces is often linked to the idea of product or career development and to learning and attending university courses;

5. The fifth type looks at cases where openness is turned into a competitive advantage, as long as it relies on a strong community. As all three cultural fields with their specific behaviors and attitudes are found here, we tend to call this type "mainstream makers."

Taking these five different types of makers as a reference point, an analysis of the Maker Movement's impact on society gains structure; we assume that the development of each type will create different results. "Social makers" are clearly of interest for inclusion activities. If actors in this field can identify makers of this type in their environment, they might be a partner that could add a tech-

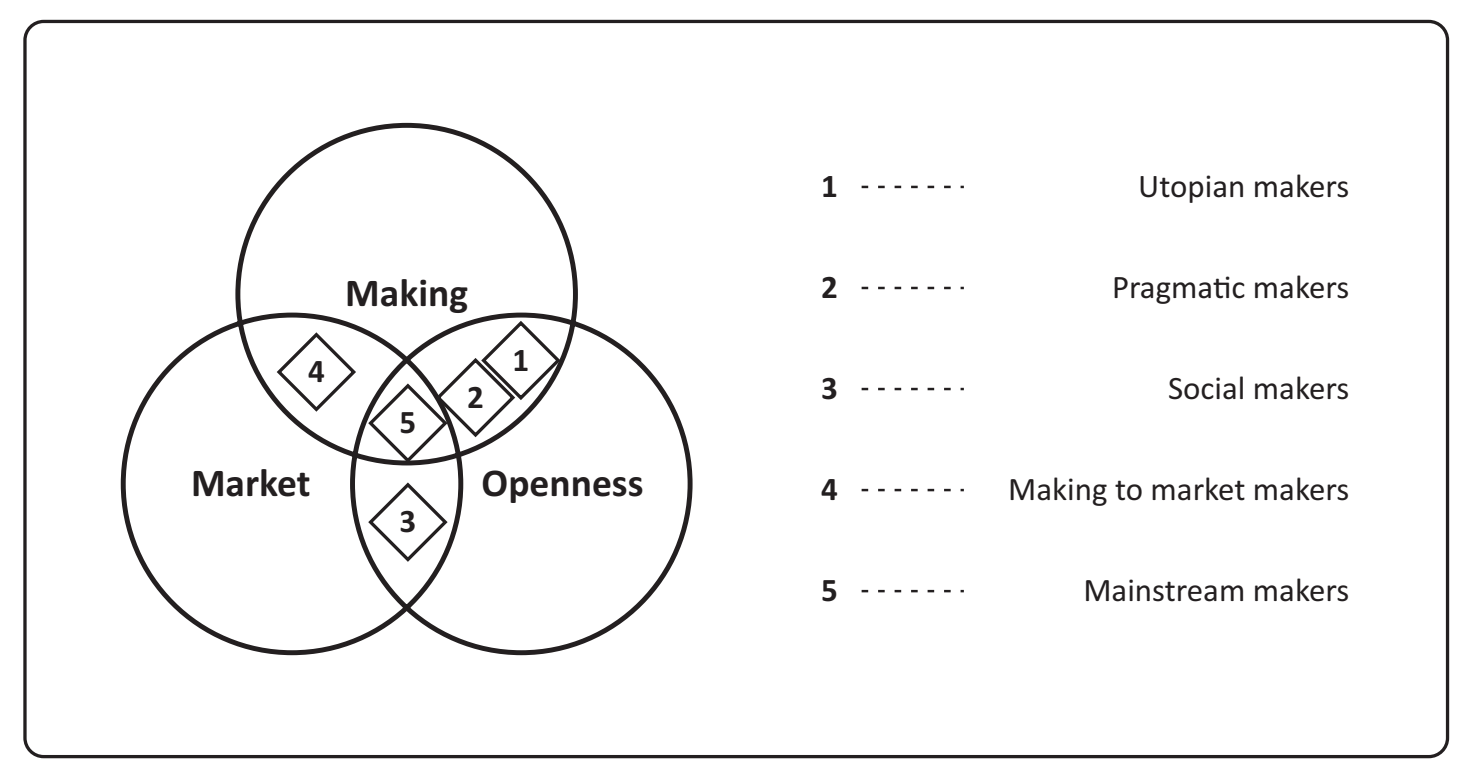

Figure 3. Maker typology. 
nological perspective to existing inclusion activities-like addressing the "digital gap." If makers with a strong market orientation expand, we can expect a stronger influence on job creation, innovation in enterprises, and economic change. If "utopian makers" should become more widely spread, an influence on societal values and a shift in mindset can be anticipated. Maker types in relation to "openness" culture could influence the societal perspective on open hard- and software, the sharing paradigm or creative commons-also of interest for educational or inclusion-oriented actors that strive to gain technological competences. "Mainstream makers" seem to be a type that is attracting a large target group without being appalling for makers stemming from other cultural fields.

Our data is a temporary snapshot. Therefore, it does not allow for predictions on the development of those types. However, Langley, Zirngiebl, Sbeih, and Devoldere (2017) suggest that makers could change their attitude and fit into another cultural field and type. The distinction of those five types allows for the prediction of pathways that could be paved and that have an implication on the inclusion of different marginalized groups.

\section{Discussion and Outlook}

The aim of the article was to explore the perceived values and impact generated by single maker communities on social dimensions. While empirical findings miss exploring associated research questions, this work is an attempt to analyze the view of the makers themselves on the shared value and social impact they create. The qualitative nature of the study, however, also has limitations in many regards. Although generalizations are difficult to make as in any qualitative study, the proposed framework can build the basis for further empirical work.

As outlined by Porter and Kramer (2011), makers create shared value between economic, social, and (often) economical dimensions. However, the study revealed that makers feel a tension between these values. Makers creating shared value act like social enterprises striving for a balance between these often conflicting goals. This sets the background for analyzing the Maker Movement's potential impact on social inclusion, as the different types of makers stand for different impacts on how to tackle inequalities.

The data were analyzed to investigate whether wider social value and impacts are perceived, specifically in the areas of education, empowerment/inclusion, and the products addressing societal challenges. Almost all types of makers show proximity to the education sectoreither as part of their own education (at a university, for example) or as a field of practice (e.g., maker spaces in disadvantaged neighborhoods) and could thus offer an educational resource for people at risk of exclusion. Our empirical data confirm the statements from different literature, that under the umbrella of STE(A)M, making embeds well in education: the interdisciplinary approach and its aims as how this pedagogy is put into practice (i.e., learning by doing, fostering creativity, self-efficacy, etc.) is highly aligned with the practice of making. Interviewees see their educational contribution in supporting a mentality shift respectively from consumerism to 'prosumerism' and preparing children for the future. However, in order to reach a broader societal impact, making needs to be introduced into formal education as well as outside school activities to reach different children.

The analysis revealed that despite efforts from the maker communities, equal participation of diverse groups could hardly be reached in most cases. As the study describes, several of the analyzed maker initiatives are targeted to specific societal challenges and finding solutions for social issues. Often these ideas deal with local solutions addressing local problems, leading to a "new localism," but some might also be taken up globally or might be interesting for other disadvantaged people as well (maker types 1, 2, and 5). As for now, the maker communities have not been in the position to attract diverse user groups on a broad basis, despite the fact that their culture is built on openness and many facilities are even free of charge.

Social value and impact seem to be closer to "utopian makers" and "social makers." Consequently, uptake of these types might also increase social value and impact. Makers oriented towards openness and making seem to steer towards educational actors, while makers with ambitions in the market and entrepreneurship seem to strive for collaborations with enterprises. This clash certainly has an influence on the impact the Maker Movement can have on social value creation.

The potential of the Maker Movement for people at risk is manifold in terms of offering access to digital fabrication tools and in terms of sharing knowledge and skills development either in the local maker space or in close collaboration between educational institutions and maker spaces. Our data show that the Maker Movement has high ambitions to be inclusive and, therefore, could be identified as an interesting new player in addressing inequalities. On the other hand, we found little experience in working with marginalized persons, describing makers as open but inexperienced in working with marginalized persons. This could be overcome by collaboration between makers and established actors with roots in tackling inequalities-such as social or educational actors of a formal and informal nature.

Given that the Maker Movement is still a fairly young phenomenon, it comes to no surprise that the highest perceived impact today takes place mainly at a micro level but rarely at a macro level. The future will show if (a growing) Maker Movement can also generate a higher impact in terms of inclusion and empowerment for marginalized groups. We assume that the current picture of the Maker Movement will outlast the period of its growth and differentiation; continuous improvement of quality, a lasting search for partnerships, and on-going clashes with existing actors will characterize the move- 
ment in the coming years. The trajectories these developments will follow are strongly bound to the development of the types of makers. If some of these types become stronger and richer in impact; this would steer the direction the overall movement is heading for.

\section{Acknowledgments}

The data presented stems from a research project funded by the European Union's research program “Horizon 2020" under grant agreement no. 688241 ("Make-IT"). The article further benefitted from another Horizon 2020 project (DOIT; grant agreement no. 770063). We acknowledge financial support by Deutsche Forschungsgemeinschaft and TU Dortmund University within the funding programme Open Access Publishing.

\section{Conflict of Interests}

The authors declare no conflict of interest.

\section{Supplementary Material}

Supplementary material for this article is available online in the format provided by the authors (unedited).

\section{References}

Awori, J., \& Lee, J. M. (2017). A Maker Movement for health: A new paradigm for health innovation. JAMA Pediatrics, 171(2), 107-108.

Bogner, A., Littig, B., \& Menz, W. (Eds.). (2009). Interviewing experts: Methodology and practice. Basingstoke: Palgrave Macmillan.

Bosse, I., Krüger, D., Linke, H., \& Pelka, B. (2019). The Maker Movement's potential for an inclusive society. In J. Howaldt, C. Kaletka, A. Schröder, \& M. Zirngiebl (Eds.), Atlas of social innovation. 2nd Volume: $A$ world of new practices (pp. 201-206). Munich: oekom.

Boyatzis, R. (1998). Transforming qualitative information: Thematic analysis and code development. Thousand Oaks, CA: Sage.

Bria, F., Gascó, M., Baeck, P., Halpin, H., Almirall, E., \& Kresin, F. (2015). Growing a digital social innovation ecosystem for Europe (DSI Final Report). London: Digital Social Innovation.

Buehler, E., Hurst, A., \& Hofmann, M. (2014). Coming to grips: 3D printing for accessibility. In ASSETS '14: Proceedings of the 16th international ACM SIGACCESS conference on computers \& accessibility (pp. 291-292). New York, NY: ACM. https://doi.org/10. $1145 / 2661334.2661345$

Creswell, J. W. (2007). Qualitative inquiry and research design: Choosing among five approaches. London: SAGE.

Devendorf, L., \& Rosner, D. K. (2015). Reimagining digital fabrication as performance art. In CHI EA '15:
Proceedings of the 33rd annual ACM conference extended abstracts on human factors in computing systems. New York, NY: ACM. https://doi.org/10.1145/ 2702613.2732507

Dougherty, D. (2016). Free to make: How the Maker Movement is changing our schools, our jobs, and our minds. Berkeley, CA: North Atlantic Books.

Drever, E. (2003). Using semi-structured interviews in small-scale research: A teacher's guide. Glasgow: Scottish Council for Research in Education.

Flick, U. (2014). An introduction to qualitative research. London: SAGE.

Franz, H.-W., Hochgerner, J., \& Howaldt, J. (2012). Challenge social innovation: An introduction. In H.-W. Franz, J. Hochgerner, \& J. Howaldt (Eds.), Challenge social innovation (pp. 1-16). Berlin: Springer.

Grimm, R., Fox, C., Baines, S., \& Albertson, K. (2013). Social innovation, an answer to contemporary societal challenges? Locating the concept in theory and practice. Innovation: The European Journal of Social Science Research, 26, 436-455.

Hochgerner, J. (2013). Social innovation. In E. G. Carayannis (Ed.), Encyclopedia of creativity, invention, innovation and entrepreneurship (pp. 1678-1686). New York, NY: Springer.

Hwang, J.-P. (2017). Maker Movement influence on students' learning motivation and learning achievement: A learning style perspective. In T.-C. Huang, R. Lau, Y.-M. Huang, M. Spaniol, \& C.-H. Yuen (Eds.), Proceedings of the SETE 2017 international symposium on emerging technologies for education. Cham: Springer.

Kohtala, C. (2015). Addressing sustainability in research on distributed production: An integrated literature review. Journal of Cleaner Production, 106, 654-668.

Kohtala, C., \& Hyysalo, S. (2015). Anticipated environmental sustainability of personal fabrication. Journal of Cleaner Production, 99, 333-344.

Korhonen, I., Parkka, J., \& van Gils, M. (2003). Health monitoring in the home of the future. IEEE Engineering in Medicine and Biology Magazine, 22(3), 66-73.

Kronauer, M. (1996). "Soziale Ausgrenzung" und "Underclass": Über neue Formen der gesellschaftlichen Spaltung ["Social exclusion" and "underclass": New forms of societal segregation]. SOFI-Mitteilungen, 24, 53-69.

Langley, D. J., Zirngiebl, M., Sbeih, J., \& Devoldere, B. (2017). Trajectories to reconcile sharing and commercialization in the Maker Movement. Business Horizons, 60(6), 783-794.

Mayring, P. (2010). Einführung in die qualitative Sozialforschung: Eine Anleitung zu qualitativem Denken [Introduction to qualitative social research: A guide to qualitative thinking]. Basel: Beltz.

Merriam, S. B. (2009). Qualitative research: A guide to design and implementation. San Francisco, CA: John Wiley \& Sons.

Miles, M. B., \& Huberman, A. M. (1994). Qualitative data analysis: An expanded sourcebook. London: SAGE. 
Millard, J., Sorivelle, M. N., Birkeholm Munk, K., Deljanin, S. R., Langley, D., van den Broek, T., . . . Zirngiebl, M. (2016). D2.1. Conceptual and methodological framework. Brussels: Make-IT. Retrieved from http://make-it.io/wordpress/wp-content/uploads/ dlm_uploads/2016/08/MAKE-IT_D2.1-1.pdf

Murray, R., Caulier-Grice, J., \& Mulgan, G. (2010). The open book of social innovation: Ways to design. develop and grow social innovation. London: NESTA.

Nascimento, S. (2014). Critical notions of technology and the promises of empowerment in shared machine shops. Journal of Peer Production, 5. Retrieved from https://publications.jrc.ec.europa.eu/ repository/handle/JRC93050

Nascimento, S., \& Pólvora, A. (2018). Maker cultures and the prospects for technological action. Science and Engineering Ethics, 24(3), 927-946.

Papavlasopoulou, S., Giannakos, M., \& Jaccheri, M. L. (2016). Empirical studies on the Maker Movement, a promising approach to learning: A literature review. Entertainment Computing, 18, 57-78.

Papert, S. (1994). The children's machine: Rethinking school in the age of the computer. New York, NY: Basic Books.

Porter, M. E., \& Kramer, M. R. (2011). The big idea: Creating shared value. How to reinvent capitalism-and unleash a wave of innovation and growth. Harvard Business Review, 89(1/2), 62-77.

Salmon, P. M., Stanton, N. A., \& Jenkins, D. P. (2017). Distributed situation awareness: Theory, measurement and application to teamwork. Boca Raton, FL: CRC Press.

Sestini, F. (2012). Collective awareness platforms: En- gines for sustainability and ethics. IEEE Technology and Society Magazine, 31, 54-62.

Silver, H. (2007). Social exclusion: Comparative analysis of Europe and Middle East youth (Middle East Youth Initiative Working Paper No. 1). Dubai: Dubai School of Government. Retrieved from http://ssrn. com/abstract $=1087432$

Thomas, D. R. (2006). A general inductive approach for analyzing qualitative evaluation data. American journal of evaluation, 27(2), 237-246.

Unterfrauner, E., \& Voigt, C. (2017). Makers' ambitions to do socially valuable things. The Design Journal. An International Journal for All Aspects of Design, 20(1), 3317-3325.

Unterfrauner, E., Voigt, C., Schrammel, M., \& Menichinelli, M. (2017). The Maker Movement and the disruption of the producer-consumer relation. In I. Kompatsiaris, J. Cave, A. Satsiou, G. Carle, A. Passani, E. Kontopoulos, S. Diplaris, \& D. McMillan (Eds.), Proceeding of the INSCl 2017 conference on internet science (113-125). Thessaloniki: Springer.

Voigt, C., Unterfrauner, E., Aslan, T., \& Hofer, M. (2019). Design Thinking with Children: The role of empathy, creativity and self-efficacy. Paper presented at the FabLearn Flagship Conference, New York.

World Bank. (n.d.). Social inclusion. The World Bank. Retrieved from https://www.worldbank.org/en/topic/ social-inclusion

$\mathrm{Yu}$, L. (2006). Understanding information inequality: Making sense of the literature of the information and digital divides. Journal of Librarianship and Information Science, 38(4), 229-252.

\section{About the Authors}
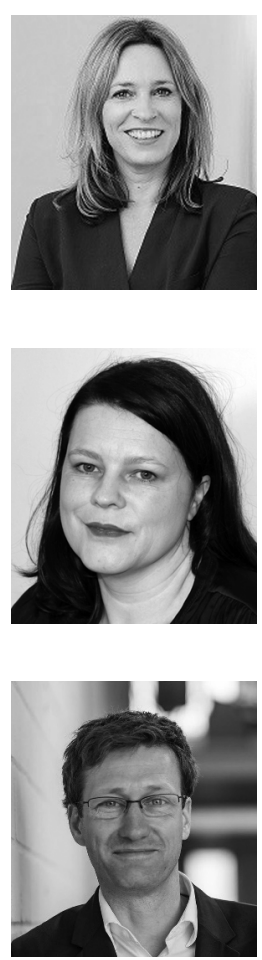

Elisabeth Unterfrauner is a Senior Researcher at the Centre for Social Innovation at the Department of Technology and Knowledge in Vienna, Austria. With a background in psychology and a PhD from the Lifelong Learning College, her research interests lie in emerging fields at the interface between society and technology and in the application of multi-method approaches.

Margit Hofer is a Senior Researcher at ZSI, carrying out a range of projects at the interface between technological and societal innovations. She holds a PhD in education and training and her field of research also involves research design allowing participative approaches and co-creation.

Bastian Pelka is a Senior Researcher at the Social Research Centre, TU Dortmund. He is the coordinator of the research unit "Labour and Education in Europe" and lecturer at the faculty of rehabilitation science. His fields of research are digital social inclusion, human-computer interaction, and social innovation. 


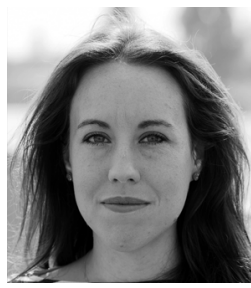

Marthe Zirngiebl is a Researcher at the Social Research Center, TU Dortmund. With a background in cultural studies and sustainability science, her current research focuses on social innovation and processes of social change. For her PhD project, she investigates how practices minimizing waste generation at an individual level diffuse in society. 